\title{
Effects of titanium doping in titanomagnetite on neptunium sorption and speciation
}

\author{
E. Miller Wylie, ${ }^{\ddagger}$ Daniel T. Olive, ${ }^{\dagger, s}$ Brian A. Powell ${ }^{\ddagger},{ }^{*}$ \\ ‡ Department of Environmental Engineering and Earth Sciences, Clemson University, Clemson, SC 29634, \\ USA \\ † Department of Chemistry, University of California, Berkeley, CA 94720, USA \\ ş Nuclear Science Division, Lawrence Berkeley National Laboratory, Berkeley, CA 94720, USA
}

\section{SUPPORTING INFORMATION}

\begin{tabular}{|c|c|c|}
\hline & CONTENTS & Pages \\
\hline & Titanomagnetite nanoparticle synthesis & SI 1 \\
\hline & Nanoparticle characterization & SI 2 \\
\hline \multirow[t]{2}{*}{ Figure S1 } & Powder X-ray diffraction of titanomagnetite nanoparticles & SI 2 \\
\hline & ICP-MS procedure & SI 3 \\
\hline Table S1 & Iron and titanium concentrations and ratios & SI 3 \\
\hline Figure S2 & Iron and titanium leaching as a function of $\mathrm{pH}$ & SI 4 \\
\hline Table S2 & Iron and titanium leaching values & SI 4 \\
\hline Table S3 & Ferrozine assay & SI 5 \\
\hline Figure S3 & Scanning electron microscopy of titanomagnetite particles & SI 6 \\
\hline Figure S4 & Energy-dispersive $\mathrm{x}$-ray spectroscopy of titanomagnetite particles & SI 7 \\
\hline \multirow[t]{2}{*}{ Table S4 } & Energy-dispersive $\mathrm{x}$-ray spectroscopy Fe/Ti ratios & SI 8 \\
\hline & Neptunium UV-vis spectroscopy & SI 9 \\
\hline \multirow[t]{2}{*}{ Figure S5 } & Neptunium stock solution spectrum & SI 9 \\
\hline & References & SI 10 \\
\hline
\end{tabular}




\section{Nanoparticle synthesis}

Titanomagnetite nanoparticles were synthesized following methods described by Pearce et al. 2012. All syntheses were performed inside a Coy anaerobic chamber with a mixed $\mathrm{N}_{2^{-}}(\sim 98 \%)$ $\mathrm{H}_{2}(\sim 2 \%)$ atmosphere with a continually monitored $\mathrm{O}_{2}$ content of less than $1 \mathrm{ppm}$. All solutions were prepared from degassed high-purity deionized (18.2 M $\Omega) \mathrm{H}_{2} \mathrm{O}$. Nanoparticles were precipitated from mixing solutions of $\mathrm{FeCl}_{2}, \mathrm{FeCl}_{3}$, and $\mathrm{TiCl}_{4}$ in $\mathrm{NH}_{4} \mathrm{OH}$ under continuous stirring. Four suspensions were prepared ranging from 0 (pure magnetite) to $\sim 0.4$ according to

$$
(1+x) \mathrm{Fe}^{2+}+(2-2 \mathrm{x}) \mathrm{Fe}^{3+}+\mathrm{xTi}^{4+}+8 \mathrm{OH}^{-} \Leftrightarrow \mathrm{Fe}_{3-\mathrm{x}} \mathrm{Ti}_{\mathrm{x}} \mathrm{O}_{4}+4 \mathrm{H}_{2} \mathrm{O}
$$

Anhydrous iron chlorides were dissolved in $0.3 \mathrm{M} \mathrm{HCl}$ and combined with titanium chloride added drop-wise from a concentrated $\mathrm{HCl}$ solution. This mixture was then slowly dropped into a continuously mechanically stirred $\mathrm{NH}_{4} \mathrm{OH}$ solution $(\mathrm{pH}>12)$ resulting in the instantaneous precipitation of $\mathrm{Fe}_{3-\mathrm{x}} \mathrm{Ti}_{\mathrm{x}} \mathrm{O}_{4}$. $\mathrm{NH}_{4} \mathrm{OH}$ concentrations were varied $(0.5-2 \mathrm{M})$ to maintain a final $\mathrm{pH}$ suspension value above 8.5 . The nanoparticles were then separated by centrifugation or magnetically and washed 3 times with and resuspended in degassed deionized $\mathrm{H}_{2} \mathrm{O}$. The suspensions were stored in the anaerobic chamber. 


\section{Nanoparticle characterization}

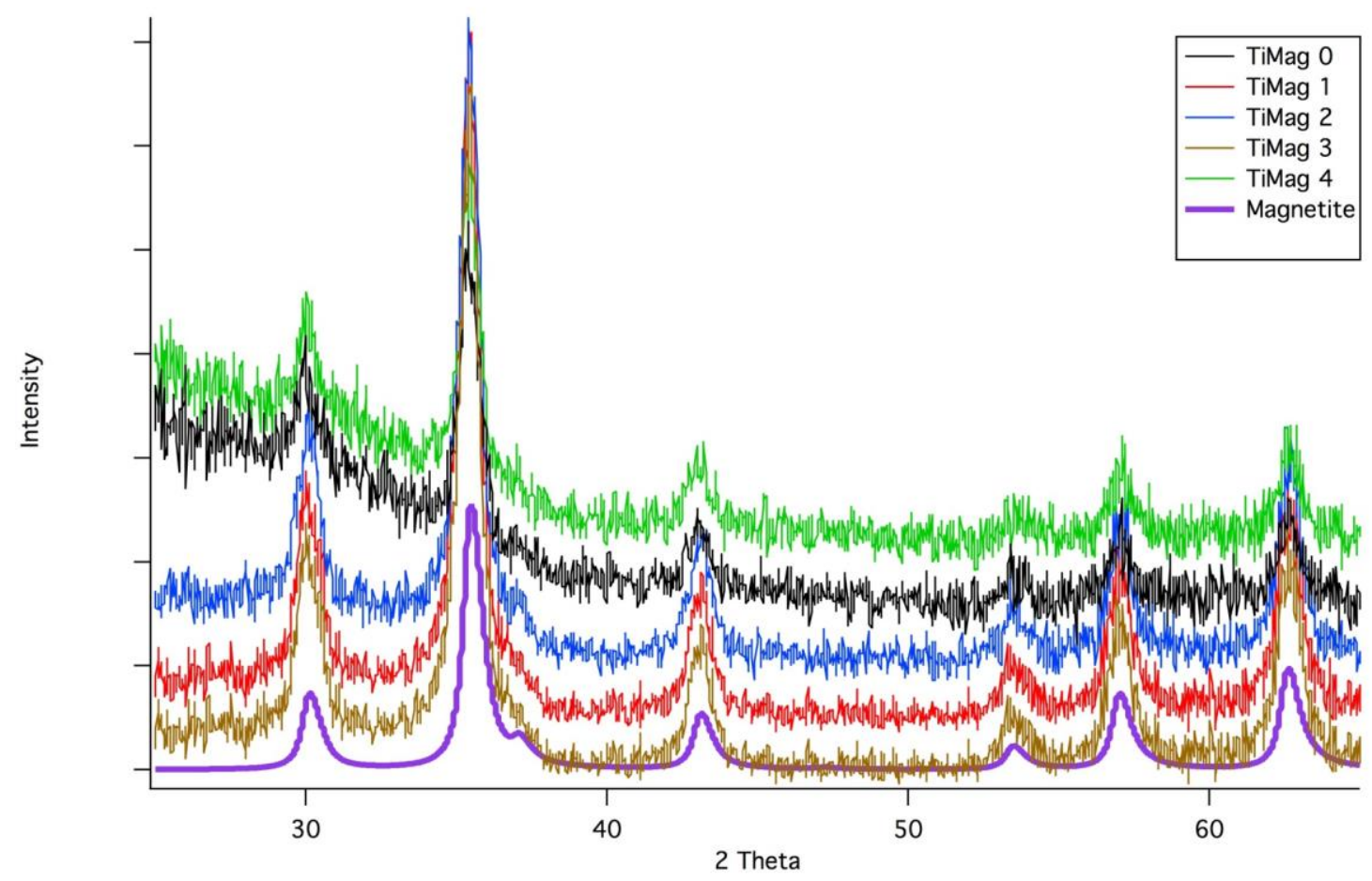

Figure S1. Powder X-ray diffraction pattern of the dried nanoparticle suspensions. All of the suspensions share the major diffraction peaks with magnetite (purple trace). 
ICP-MS Procedure

All samples, blanks, and standards were prepared in $2 \% \mathrm{HNO}_{3}$ solutions. A Thermo Scientific XSeries 2 ICP-MS internally standardized with 10 ppb Li, Sc, 50 ppb Ga, In, Y, Tb, Bi was used for all $\mathrm{Fe}$ and $\mathrm{Ti}$ measurements. $\mathrm{A} \mathrm{Pu}^{242}$ internal standard was used for $\mathrm{Np}$ measurements.

Table S1. Iron and titanium concentrations and ratios

\begin{tabular}{|c|c|c|c|c|c|}
\hline Sample & Fe $(\mathrm{ppm})$ & $\mathrm{Ti}(\mathrm{ppm})$ & $\mathrm{Fe} / \mathrm{Ti}$ & Ideal & $\mathrm{Ti}$ \\
\hline TiMag 0 & 1484.8 & & & & \\
\hline TiMag 1 & 1384.5 & 57.6 & 24.0 & 29 & 0.12 \\
\hline TiMag 2 & 1455.5 & 119.5 & 12.1 & 14 & 0.23 \\
\hline TiMag 3 & 1451.7 & 187.9 & 7.7 & 9 & 0.34 \\
\hline TiMag 4 & 968.3 & 176.4 & 5.4 & 6.5 & 0.46 \\
\hline
\end{tabular}

Suspensions were dissolved in $6.5 \mathrm{M} \mathrm{HCl}$ and mixed overnight. Aliquots were then diluted into $2 \% \mathrm{HNO}_{3}$ solutions for ICP-MS analyses. 
Leached values are reported as the ratio of iron and titanium measured in the ICP-MS samples (C) to the calculated amount that would be present if there were no dissolution (Co) at the end of the 30-day experiments. Error bars represent 2 standard deviations.

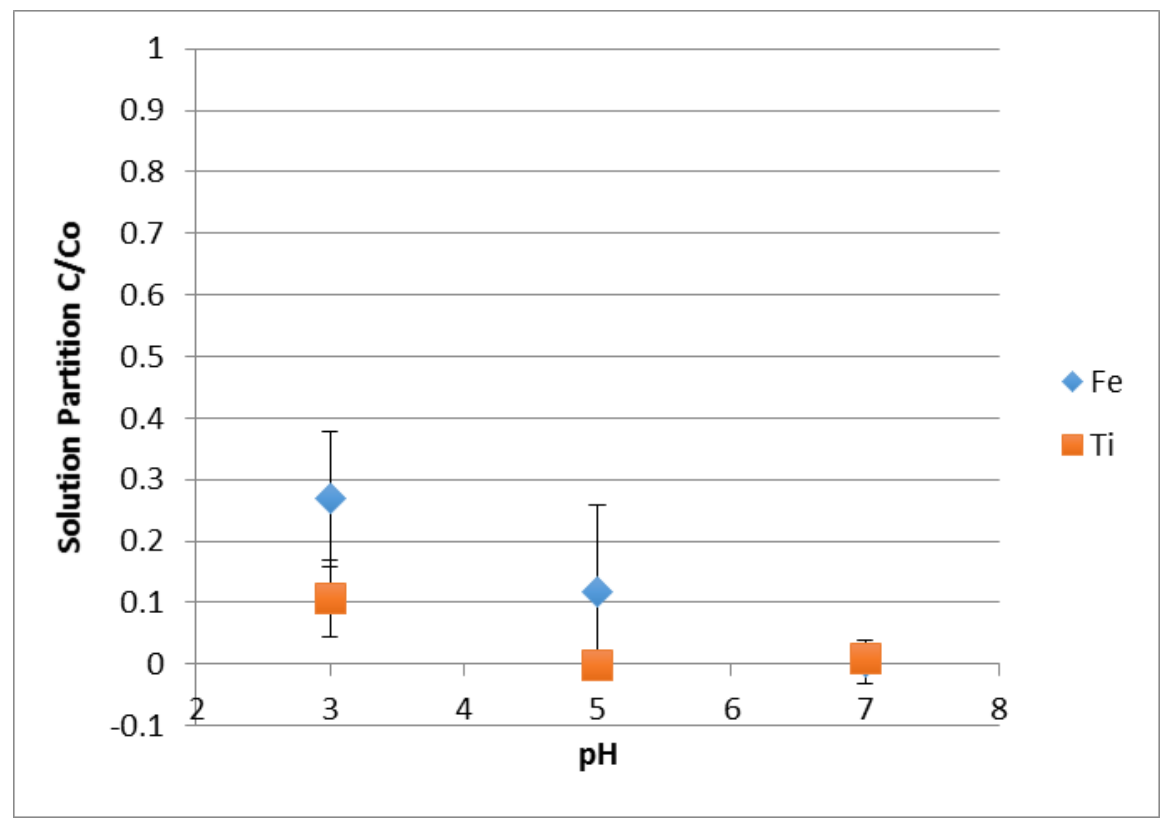

Figure S2. Iron and titanium leaching as a function of $\mathrm{pH}$. Each point represents all of the Ti loading values (T0-T4).

Table S2. Iron and titanium leaching values as \% leached at all Ti loading values

\begin{tabular}{|c|c|c|}
\hline $\mathrm{pH}$ & $\mathrm{Fe}$ & $\mathrm{Ti}$ \\
\hline 3 & 26.8 & 10.6 \\
\hline 5 & 11.7 & 0 \\
\hline 7 & 0.31 & 0 \\
\hline
\end{tabular}




\section{Ferrozine Assay}

Nanoparticle suspensions were analyzed for $\mathrm{Fe}^{2+}$ and $\mathrm{Fe}^{3+}$ content using the Ferrozine method (Stookey 1970). Suspensions were dissolved in $6 \mathrm{M} \mathrm{H}_{2} \mathrm{SO}_{4}$ and mixed overnight. Aliquots were then removed and spiked with $10 \mathrm{mM}$ Ferrozine and an ammonium acetate buffer and standardized with $\left(\mathrm{NH}_{4}\right)_{2} \mathrm{Fe}\left(\mathrm{SO}_{4}\right)_{2}$. Total Fe was measured by spiking aliquots with $1.4 \mathrm{M}$ hydroxylamine hydrochloride in $1 \mathrm{M} \mathrm{HCl}$. Absorption was measured at $565 \mathrm{~nm}$ with a VarianCary Model 50 UV-Vis Spectrometer.

Table $\mathrm{S} 3 . \mathrm{Fe}^{2+} / \mathrm{Fe}^{3+}$ ratios

\begin{tabular}{|c|c|c|}
\hline Sample & $\mathrm{Fe}^{2+} / \mathrm{Fe}^{3+}$ & Ideal \\
\hline TiMag 0 & 0.563 & 0.5 \\
\hline TiMag 1 & 0.673 & 0.676 \\
\hline TiMag 2 & 0.741 & 0.851 \\
\hline TiMag 3 & 0.858 & 1.113 \\
\hline TiMag 4 & 1.024 & 1.195 \\
\hline
\end{tabular}




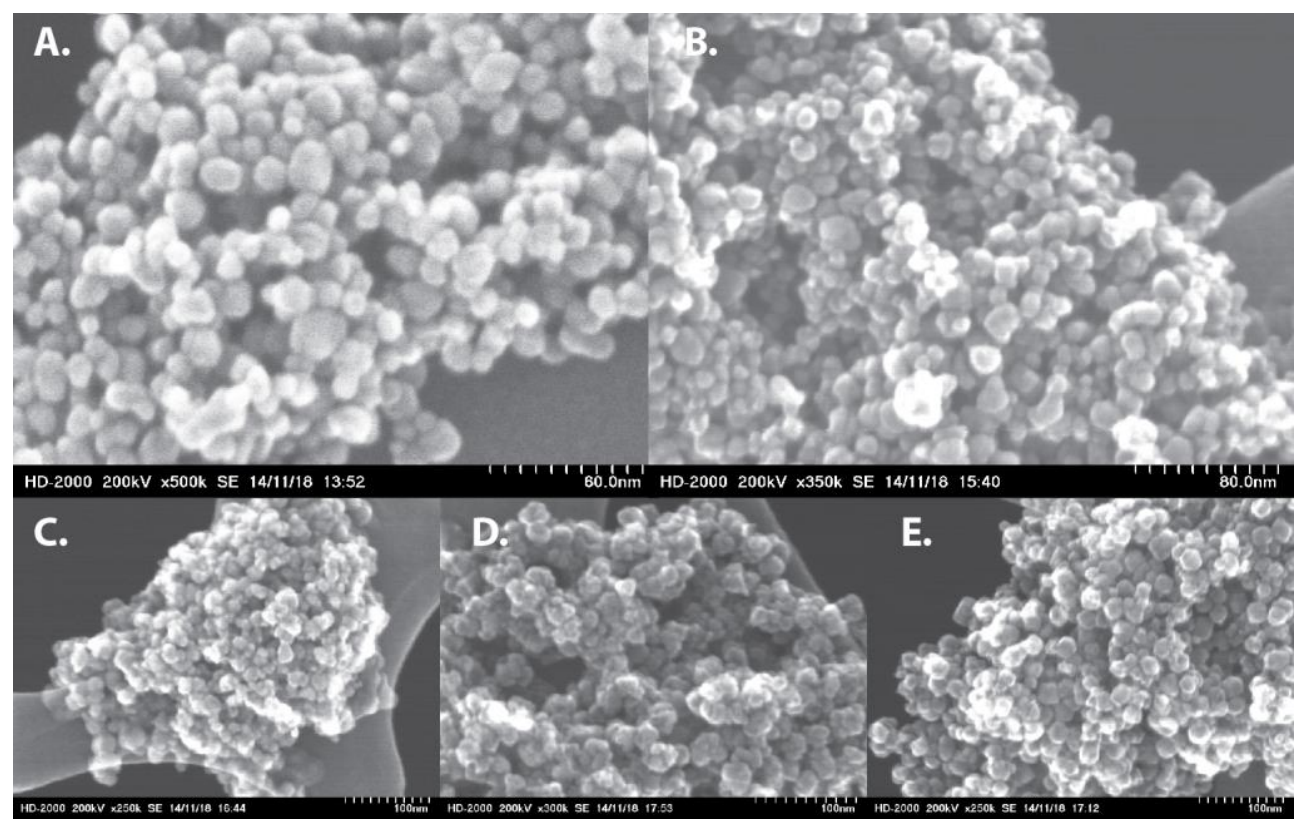

Figure S3. Scanning transmission electron microscopy (STEM) of the nanopartilces (magnetite A, TiMag 1 B, TiMag 2 C, TiMag 3 D, TiMag 4, E). Titanium doping increases with each image A-E. Note individual figures have different scales. 

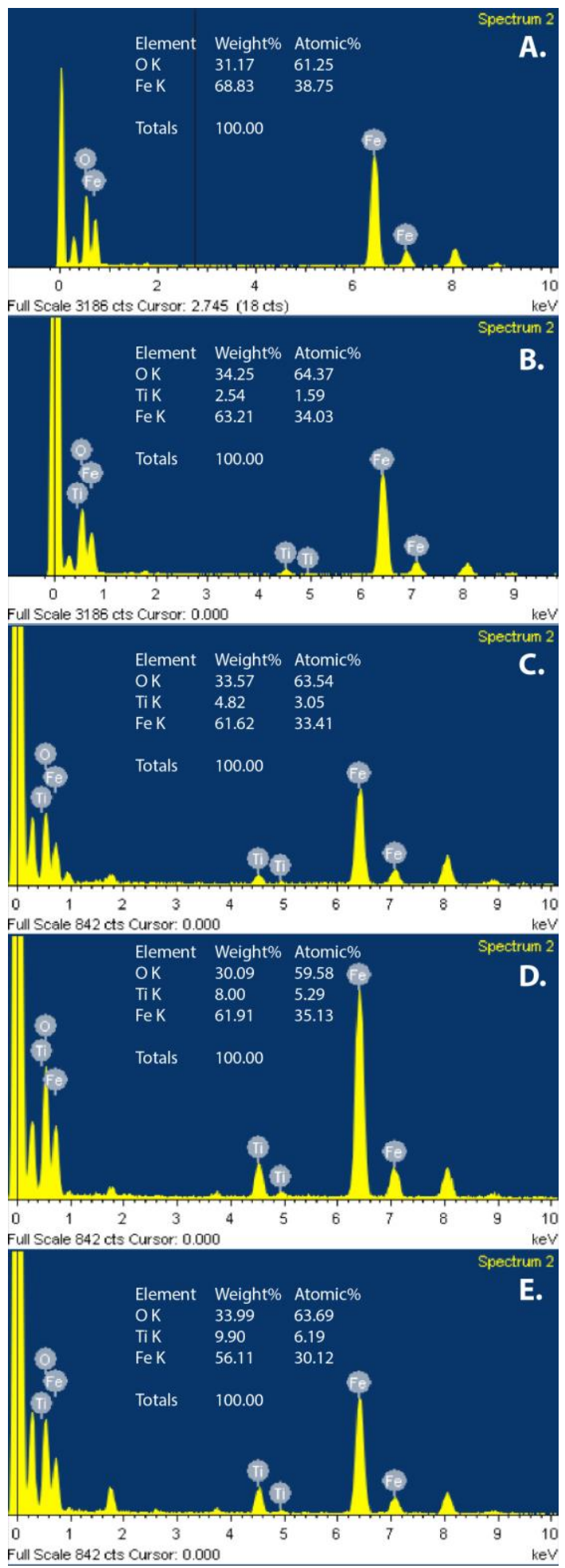

Figure S4. Energy-dispersive spectroscopy of the nanoparticles. Titanium concentration increases A-E. 
Table S4. Comparison of EDS and ICP-MS Fe/Ti ratios

\begin{tabular}{|c|c|c|}
\hline Sample & EDS Fe/Ti & ICPMS Fe/Ti \\
\hline TiMag 1 & 24.88 & 24.0 \\
\hline TiMag 2 & 12.78 & 12.1 \\
\hline TiMag 3 & 7.73 & 7.7 \\
\hline TiMag 4 & 5.66 & 5.4 \\
\hline
\end{tabular}




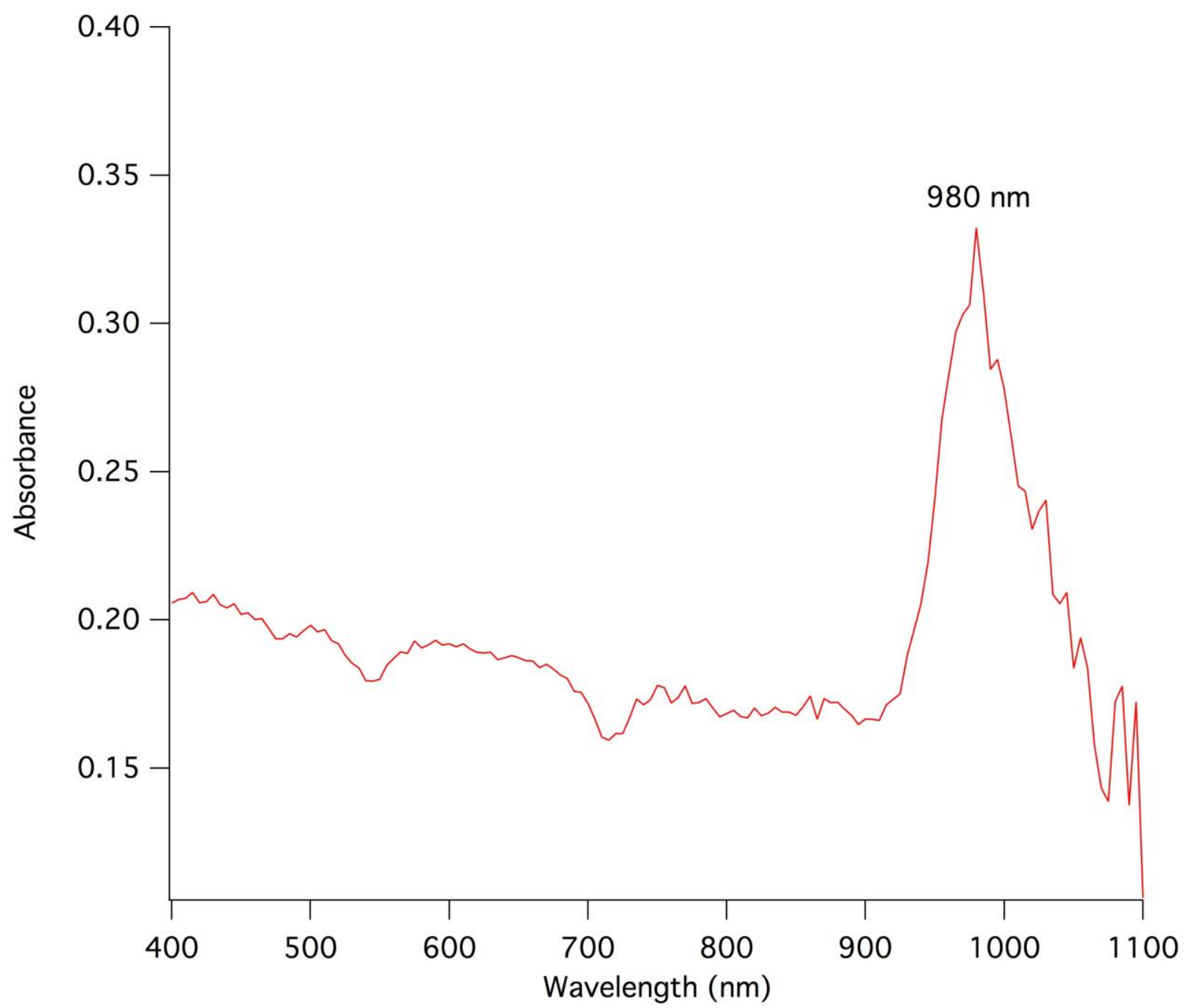

Figure S5. UV-vis spectrum of the neptunium stock solution with a peak at $980 \mathrm{~nm}$ indicating the presence of $\mathrm{NpO}_{2}{ }^{+}$. Other peaks associated with $\mathrm{NpO}_{2}{ }^{2+}$ were not evident. 


\section{References}

Pearce, C. I.; Qafoku, O.; Liu, J.; Heald, S. M.; Arenholz, E.; Kukkadapu, R. K.; Gorski, C. A.; Henderson, C. M. B.; Rosso, K. M. Synthesis and properties of titanomagnetite $\left(\mathrm{Fe}_{3-x} \mathrm{Ti}_{x} \mathrm{O}_{4}\right)$ nanoparticles: A tunable solid-state $\mathrm{Fe}(\mathrm{II} / \mathrm{III})$ redox system J. Colloid Interface Sci. 2012, 387 24-38.

Stookey, L. L. Ferrozine-A new spectrophotometric reagent for iron Analytical Chemistry 1970, 42 (7) $779-781$.

Joshi, S. R. Lanthanum fluoride coprecipitation technique for the preparation of actinides for alpha-particle spectrometry Journal of Radioanalytical and Nuclear Chemistry 1985, 9 (2) 409414. 